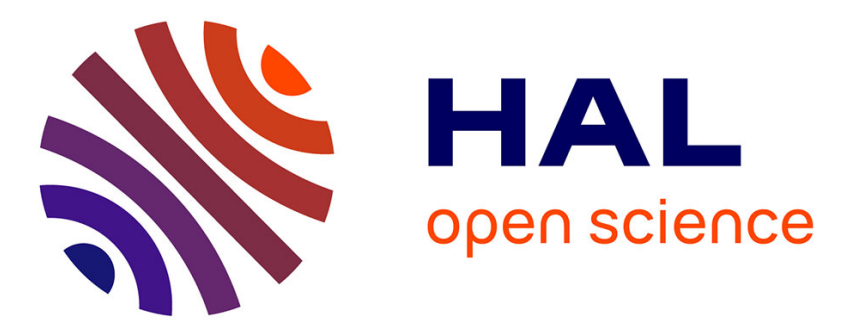

\title{
Structural investigation and mechanical properties of a representative of a new class of materials: nanograined metallic glasses.
}

N. Chen, D.V. Louzguine-Luzgin, G.Q. Xie, P. Sharma, J.H. Perepezko, M. Esashi, A.R. Yavari, A. Inoue

\section{To cite this version:}

N. Chen, D.V. Louzguine-Luzgin, G.Q. Xie, P. Sharma, J.H. Perepezko, et al.. Structural investigation and mechanical properties of a representative of a new class of materials: nanograined metallic glasses.. International Journal of Nanotechnology, 2012, 24 (4), 10.1088/0957-4484/24/4/045610 . hal-00794220

\section{HAL Id: hal-00794220 \\ https://hal.science/hal-00794220}

Submitted on 12 May 2020

HAL is a multi-disciplinary open access archive for the deposit and dissemination of scientific research documents, whether they are published or not. The documents may come from teaching and research institutions in France or abroad, or from public or private research centers.
L'archive ouverte pluridisciplinaire HAL, est destinée au dépôt et à la diffusion de documents scientifiques de niveau recherche, publiés ou non, émanant des établissements d'enseignement et de recherche français ou étrangers, des laboratoires publics ou privés. 


\title{
Structural investigation and mechanical properties of a representative of a new class of materials: nanograined metallic glasses
}

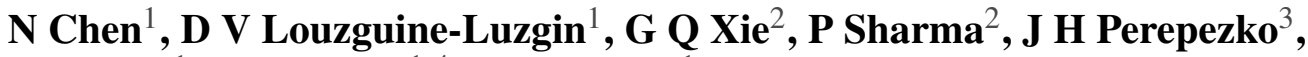 \\ M Esashi ${ }^{1}$, A R Yavari ${ }^{1,4}$ and A Inoue $^{1}$ \\ ${ }^{1}$ WPI Advanced Institute for Materials Research, Tohoku University, Sendai 980-8577, Japan \\ ${ }^{2}$ Institute for Materials Research, Tohoku University, Sendai 980-8577, Japan \\ ${ }^{3}$ Department of Materials Science and Engineering, University of Wisconsin-Madison, 1509 University \\ Avenue, Madison, WI 53706, USA \\ ${ }^{4}$ SIMAP-CNRS, Institut Polytechnique de Grenoble, BP 75, St-Martin-d'Hères Campus, F-38402, \\ France
}

E-mail: chenn@wpi-aimr.tohoku.ac.jp and dml@wpi-aimr.tohoku.ac.jp (D V Louzguine-Luzgin)

\begin{abstract}
A new class of materials: Au-based nanograined metallic glasses (NGMGs) were synthesized using magnetron sputtering with powder targets. A detailed study by x-ray diffraction and high-resolution transmission electron microscopy (TEM) documents the unique nanoscale granular structure of the Au-based NGMG. This material inherited the good mechanical properties of metallic glasses, showing a high hardness of $\sim 5.3 \mathrm{GPa}$ and a low elastic modulus of $\sim 79 \mathrm{GPa}$. In addition, in contrast to most MGs the nanoglassy particles can deform along the loading direction, exhibiting unique tensile elongation up to $100 \%$. During thermal crystallization of NGMG material, even smaller sized Au solid solution nanocrystals are formed within the glassy nanograins, offering a new way for production of the nanocomposites with tailored structural length scales.
\end{abstract}

\section{Introduction}

The properties of a material are determined by its internal structure. This relationship has guided numerous attempts to produce new structures for improving the performance of materials. In light of this, the birth of metallic glasses has triggered intensive research on their physical, chemical and mechanical properties due to their distinct structural difference from the crystalline counterparts [1-6]. The usual way to produce a metallic glass is cooling of a viscous metallic liquid, which can yield bulk metallic glasses (BMGs) [7, 8]. Owing to their attractive mechanical properties such as high strength and relatively low elastic moduli, BMGs hold tremendous promise for applications in engineering fields [9-12]. However, few BMG alloys exhibit macroscopic tensile ductility, which dramatically reduces their utility for load-bearing structural applications [13, 14]. This undesirable property stems from the unavoidable shear localization associated with the BMGs' macroscopically uniform microstructure. To address this issue, the most successful way is to develop metallic-glass-matrix composites by introducing ductile crystalline phases [15-17], but the improved ductility, unfortunately, is always accompanied by a trade off in the strength.

Nanocrystalline materials, with a grain size of typically $<100 \mathrm{~nm}$, show unique properties derived from a large fraction of grain boundaries compared to coarse-grained polycrystalline counterparts. Usually with decreasing the 
grain size nanocrystalline metals show higher strength, in accord with the Hall-Petch relationship [18, 19]. In light of the grain size-strength effect in nanocrystalline materials, one can expect that a material with nanometer-sized grains having a glassy structure may show enhanced strength and ductility [20, 21]. Recently, we produced such a $\mathrm{Au}_{52} \mathrm{Ag}_{5} \mathrm{Pd}_{2} \mathrm{Cu}_{25} \mathrm{Si}_{10} \mathrm{Al}_{6}$ nanograined metallic glass (NGMG) with clear glass-glass interfaces [22]. In this paper, we report on the interrelationship between the atomic structure and the enhanced mechanical properties of this Au-based NGMG material.

\section{Experimental procedure}

The $\mathrm{Au}_{46} \mathrm{Ag}_{6} \mathrm{Pd}_{2} \mathrm{Cu}_{27} \mathrm{Si}_{14} \mathrm{Al}_{5}$ (NGMG1) and $\mathrm{Au}_{52} \mathrm{Ag}_{5} \mathrm{Pd}_{2}$ $\mathrm{Cu}_{25} \mathrm{Si}_{10} \mathrm{Al}_{6}$ (NGMG2) were prepared using conventional magnetron sputtering. The detailed procedure for the formation of the NGMGs can be found in [22]. The role of the synthetic parameters on the structure of the film is discussed below.

The structure of the Au-based thin films was investigated by synchrotron radiation x-ray diffraction in transmission and high-resolution transmission electron microscopy (HRTEM) methods. The mechanical testing was carried out by using both a nanoindentation technique (Ubi 1, nanomechanical test instrument, Hysitron, Inc., USA) and a NEC MH4000 tester (a mechanical properties tester for thin films). Annealing treatment on the samples was done in a vacuum furnace at $463 \mathrm{~K}$. The surface morphological evolution after the annealing was investigated by scanning electron microscope (SEM) examination. The chemical compositional analysis was conducted by an energy dispersive x-ray spectrometry (EDS) device attached to the SEM. The thermal properties of the samples were measured by a differential scanning calorimetry (DSC) method. The density measurements using the Archimedean principle were performed with a microbalance having a sensitivity of $0.01 \mu \mathrm{g}$. $N$-Tridecane was used as a liquid for measurements. The weight of every sample was measured three times in both the liquid and air and then the average values were applied to calculate the densities.

\section{Results and discussion}

\subsection{As-deposited structure}

The glassy nature of the as-deposited Au-based NGMGs was confirmed by (HR) TEM methods as illustrated in figure 1. Both $\mathrm{Au}_{46} \mathrm{Ag}_{6} \mathrm{Pd}_{2} \mathrm{Cu}_{27} \mathrm{Si}_{14} \mathrm{Al}_{5}$ (NGMG1) and $\mathrm{Au}_{52} \mathrm{Ag}_{5} \mathrm{Pd}_{2} \mathrm{Cu}_{25} \mathrm{Si}_{10} \mathrm{Al}_{6}$ (NGMG2) samples presented a nanometer-sized granular structure. The microstructure that is presented in figures 1(a) and (f) illustrates the granular morphology with both dark and light contrasts. The dark contrast area represents amorphous regions of high density (i.e. grains) while the light contrast that was between the amorphous grains highlighted in figures $1(d)$ and (i) represents amorphous regions of low density (i.e. interface). Using a lognormal fit of the particle size distributions (figures 1(a) and (f)), the spheroid-like nanoparticles of NGMG1 and
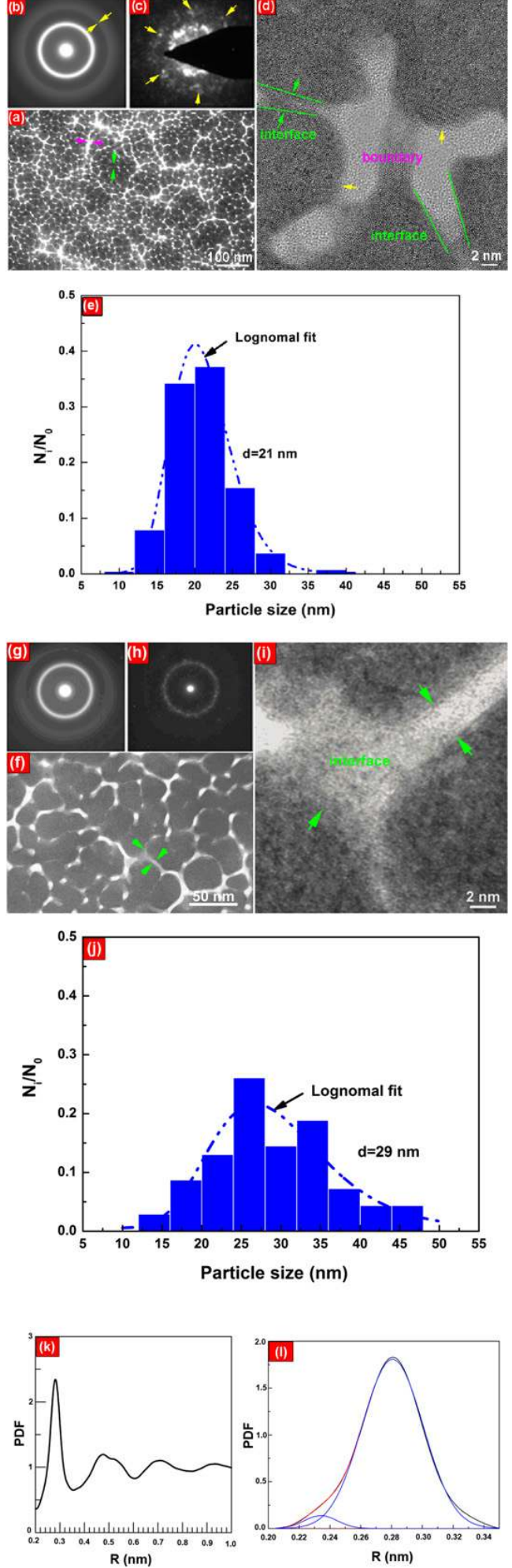

Figure 1. Bright-field TEM images of NGMG1 (a) and NGMG2 (f); the particle size distribution analysis of NGMG1 (e) and NGMG2 (j); selected area electron diffraction (SAED) patterns of NGMG1 (b) and NGMG (g), respectively; the typical nanobeam diffraction (NBD) patterns of NGMG1 (c) and NGMG2 (h) (probe size $3 \mathrm{~nm}$ ); HRTEM images illustrating the interfaces between glassy particles in NGMG1 (d) and NGMG2 (i). The synchrotron $\mathrm{x}$-ray radiation measurements in transmission of NGMG2. (k) Pair distribution functions (PDFs) derived from $Q \cdot I(Q)$ by the usual Fourier transformation and (1) a part in the first coordination shell fitted with two Gaussian functions. 
NGMG2 samples have a mean grain size of $21 \mathrm{~nm}$ and $29 \mathrm{~nm}$ (figures 1(e) and (j)), respectively. The larger size of the NGMG2 sample may be attributed to its higher Au content, which promotes clustering of nanoparticles [23]. The selected area electron diffraction (SAED) pattern of NGMG1 shows a weak contrast overlapping on the amorphous ring as indicated by yellow arrows, possibly due to the presence of nanocrystals (figure 1(b)). The sharp diffraction spots in the nanobeam electron diffraction (NBED) pattern confirmed the existence of the nanocrystals (figure 1(c)). The corresponding layer of very fine ordered zones is evident at the interfaces among the particles (marked by yellow arrows in figure 1(d)).

In the case of the NGMG2 sample, no sharp rings, but only diffuse haloes can be found, as shown in figure $1(\mathrm{~g})$, implying that the nanograins are indeed glassy (figure 1(f)). The NBED pattern from the interface structure demonstrates only a diffuse halo (figure $1(\mathrm{~h})$ ), that indicates that a fully glassy structure is obtained even at the interfaces of NGMG2. HRTEM images show maze-like patterns that are typical for an amorphous structure (figure 1(i)), further confirming that both the nanograins and the grain interfaces are glassy.

To further probe the structural characteristics of the fully glassy NGMG2 sample, synchrotron x-ray radiation measurements were carried out in transmission. The intensity, $I(Q)$ versus scattering vector $Q$ plots were processed and the resulting pair distribution functions (PDF) were derived as shown in figure $1(\mathrm{k})$, revealing a typical feature of an amorphous structure. The first peak was fitted with two Gaussian functions (figure 1(1)). The results of fitting indicate that the first maximum of the pair distribution function (PDF) consists of two subpeaks: one at $0.2341 \mathrm{~nm}$, the other at $0.2807 \mathrm{~nm}$, representing the mean first nearest atomic distances. The first subpeak position is between the sum of Goldschmidt atomic radii of the $\mathrm{Si}-\mathrm{Si}$ pair $(0.232 \mathrm{~nm})$ and the $\mathrm{Cu}-\mathrm{Si}$ pair $(0.245 \mathrm{~nm})$, and possibly attributed to these atomic pairs. The second subpeak position is larger than the interatomic distance of $\mathrm{Au}-\mathrm{Si}(0.261 \mathrm{~nm})$ and may represent the $\mathrm{Au}-\mathrm{Au}$ separation $(0.288 \mathrm{~nm})$. For the second maximum (from 0.35 to $0.61 \mathrm{~nm}$ ) the positions of subpeaks are at 0.4708 and $0.5408 \mathrm{~nm}$, respectively. The positions of the subpeaks in the second maximum correspond very closely to those in a $\mathrm{Pd}_{81} \mathrm{Si}_{19}$ alloy studied earlier [24], and are likely attributed to the atomic size of the main component gold $(0.144 \mathrm{~nm})$ that is also close to that of $\operatorname{Pd}(0.137 \mathrm{~nm})$. The above results indicate the formation of a densely packed structure within the glassy particles.

\subsection{Thermal stability}

The DSC curve of NGMG2 demonstrates a clear glass transition temperature $T_{\mathrm{g}}$ of $420 \mathrm{~K}$, the initiation crystallization temperature $T_{\mathrm{x}}$ of $453 \mathrm{~K}$, the peak crystallization temperatures $T_{\mathrm{p} 1}$ of $463 \mathrm{~K}$ and $T_{\mathrm{p} 2}$ of $520 \mathrm{~K}$, respectively (figure 2(a)). The supercooled liquid region $\Delta T\left(=T_{\mathrm{x}}-T_{\mathrm{g}}\right)$ is $33 \mathrm{~K}$. Based on these data, NGMG2 was annealed at $463 \mathrm{~K}$ for $15 \mathrm{~min}$ and $1.5 \mathrm{~h}$, respectively. The XRD patterns of the as-deposited and the annealed samples are shown in figures 2(c)-(e). After annealing for $15 \mathrm{~min}$ the sample still
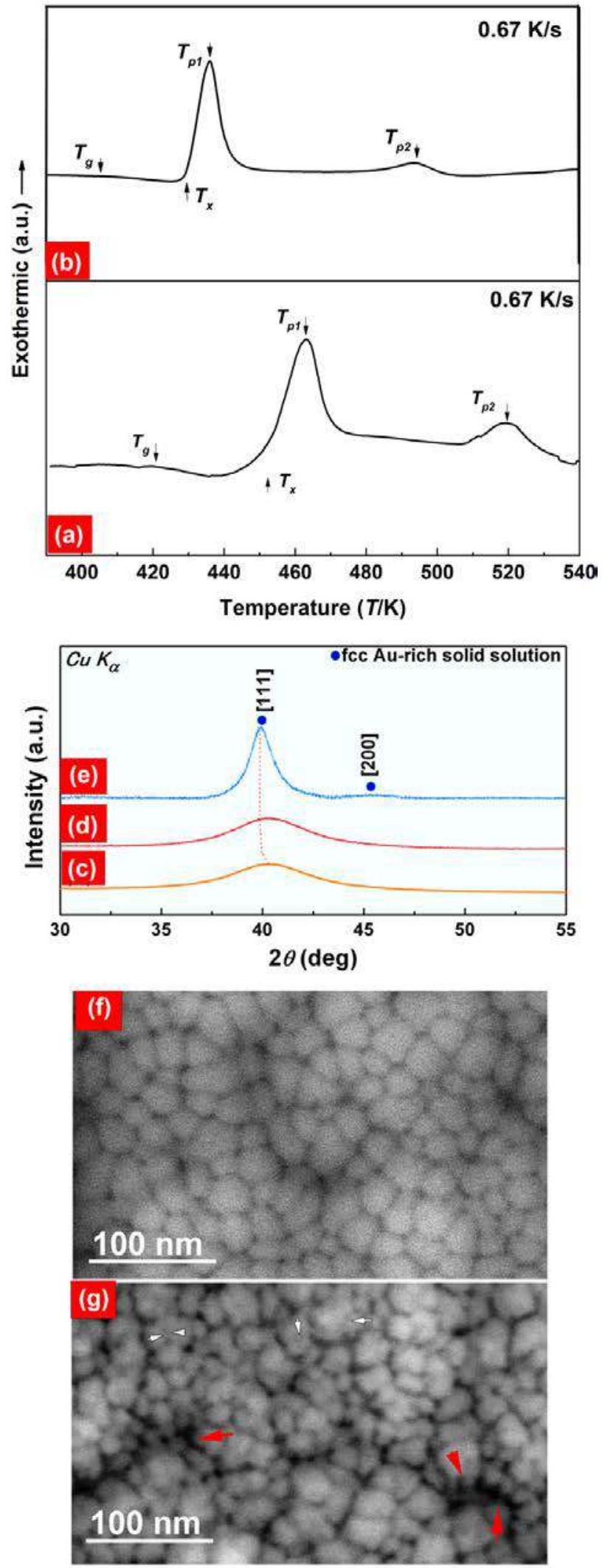

Figure 2. DSC curves of (a) the as-deposited Au-based NGMG2 and (b) the corresponding glassy ribbons. XRD patterns of (c) the as-deposited Au-based NGMG2 and the samples annealed at $463 \mathrm{~K}$, (d) for $15 \mathrm{~min}$ and (e) for $1.5 \mathrm{~h}$; (f) and (g) are the corresponding SEM images of samples (c) and (d). 
shows the same broad peak as the original sample, indicating that no obvious crystallization takes place at this stage. With increasing annealing time to $1.5 \mathrm{~h}$, the first broad diffraction peak becomes apparently narrower and the peak position shifts to a lower diffraction angle, clearly demonstrating the crystallization of the Au-based NGMG2. The crystalline phase is indexed to be a fcc Au-rich solid solution as shown in figure 2(e). The evolution of structural morphology accompanying the precipitation of nanocrystals is shown in figures 2(f) and (g). The crystalline phase nucleates at the grain interfaces and within the grain interior. Voids are formed between the glassy grains if nucleation takes place at the interfaces due to volume contraction, as illustrated by the red arrows in figure $2(\mathrm{~g})$. As indicated by the white arrows in figure $2(\mathrm{~g})$, the nanocrystals also precipitated within the nanometer-sized glassy grains. Basically, the length scale of the precipitated crystals depends on the original glassy grain size, which offers a new option to produce very fine crystals with controllable size. It is important to stress here that the nanograined glassy particles are very stable compared to the conventional homogeneous glassy structure since no clear structural difference can be detected even after annealing at the peak crystallization temperature for $15 \mathrm{~min}$ (figure 2(d)).

Such a high stability of NGMG2 is also supported by the DSC curve of the corresponding $\mathrm{Au}_{52} \mathrm{Ag}_{5} \mathrm{Pd}_{2} \mathrm{Cu}_{25} \mathrm{Si}_{10} \mathrm{Al}_{6}$ ribbons (figure 2(b)). Compared to NGMG2, the glassy ribbon samples prepared by melt-spinning display much lower $T_{\mathrm{g}}$ of $405 \mathrm{~K}, T_{\mathrm{x}}$ of $430 \mathrm{~K}, T_{\mathrm{p} 1}$ of $436 \mathrm{~K}$ and $T_{\mathrm{p} 2}$ of $494 \mathrm{~K}$, respectively. A significantly narrower $\Delta T$ of $25 \mathrm{~K}$ shown by the ribbons suggests their reduced thermal stability in comparison with NGMG2. Very recently, Priestley and co-workers reported a similar nanoglobular structure formed in a polymer glass which demonstrated ultrahigh kinetic stability [25]. Distinct from the usual way of cooling a liquid, the alternative route to make a glass from a gaseous phase may significantly alter the molecular packing by allowing surface deposits to reside in low energy configurations, thereby giving rise to a dramatic change in both structure and properties [26]. Simultaneously the annealing-induced nanocrystals are also quite stable against coarsening as evidenced by the SEM image shown in figure $2(\mathrm{~g})$.

\subsection{Nanograin synthesis}

The sputtering technique used in the present study can provide a cooling rate of up to $10^{12} \mathrm{~K} \mathrm{~s}^{-1}$, which is around six orders of magnitude higher than the typical cooling rate for the melt-spinning method. At a cooling rate of this order, a computer simulation result predicted that single component $\mathrm{Cu}$ glassy droplets may be formed [27]. Usually high cooling rate leads to a less stable glassy structure due to the short relaxation time during the preparation process. However, unusually stable organic glasses and polymer glasses have been prepared by vapor deposition with low deposition rates [28-31]. In addition, the increase in stability of the nanostructured polymer glassy film was confirmed to originate from the property of the nanoglobules that constitute the film [25]. With many metallic glasses that require synthesis by rapid melt quenching, a slow deposition rate will yield crystalline formation. But the high glass forming ability of BMGs enables amorphous alloy formation at low deposition rates. As a result, a slow deposition rate of around $1 \mathrm{~nm} \mathrm{~s}^{-1}$ coupled with an enhanced surface mobility permits the attainment of low energy configurations of amorphous nanoparticles and thus promotes the formation of the Au-based NGMG thin films.

It is important to note that we used a cyclic deposition process instead of the usual continuous sputtering. Namely, we stopped sputtering for $10 \mathrm{~min}$ after every $10 \mathrm{~min}$ continuous sputtering. The purpose of this cyclic deposition mainly has two aspects. One is to avoid a high temperature rise of the substrate. The other is to provide sufficient time for the glassy particles to nucleate and grow due to the high atomic mobility on the surface.

With the magnetron sputtering technique, the microstructure of thin films is mainly controlled by the applied deposition rate, the rotation angle of the substrate and the substrate temperature. In our case, the substrate surface orientation is parallel to that of the target. Meanwhile, there is no cooling or heating system attached to the substrate. Therefore, the only changeable parameter is the deposition rate, which can be tuned by two key factors including the applied power for sputtering and the distance between the target and the substrate. To simplify the process, the distance between the substrate and the target is also fixed to be $110 \mathrm{~cm}$. Hence, the parameter applied to change the deposition rate is only the input power of sputtering. In order to clarify the correlation between the sputtering power and the microstructure, we used different values of the applied power on deposition. As shown in figure 3(a), the deposition rate $v$ decreases with decreasing the power $P$. However, the basic structural constituents for all the samples are still glassy particles, at least within the power values used in the present study (figures 3(b)-(e)). One can also note that in the samples prepared at lower input power, the particles aggregated into bigger clusters at the same deposition time.

\subsection{Mechanical properties}

The density of the Au-based NGMG2 is measured to be $13.33 \mathrm{~g} \mathrm{~cm}^{-3}$. For an as-cast $\mathrm{Au}_{52} \mathrm{Ag}_{5} \mathrm{Pd}_{2} \mathrm{Cu}_{25} \mathrm{Si}_{10} \mathrm{Al}_{6}$ rod sample with a diameter of $3 \mathrm{~mm}$ and an almost fully glassy structure, the density is $\sim 14.21 \mathrm{~g} \mathrm{~cm}^{-3}$. The density difference between NGMG2 and the bulk sample is $\sim 6.2 \%$, which is much larger than the density reduction (usually $<0.5 \%$ ) due to structural relaxation of metallic glasses [32]. The density variation between nanoglasses and relaxed glasses could reach up to $15 \%$ before voids are found, which may lead to a large property change of the materials [33].

Nanoindentation tests were performed to evaluate the mechanical properties. For comparison, we produced $\mathrm{Au}_{61} \mathrm{Ag}_{5} \mathrm{Pd}_{1} \mathrm{Cu}_{19} \mathrm{Si}_{7} \mathrm{Al}_{7}$ nanocrystalline metallic alloy (NCMA) thin films. The SEM images of the crystallized $\mathrm{Au}_{52} \mathrm{Ag}_{5} \mathrm{Pd}_{2} \mathrm{Cu}_{25} \mathrm{Si}_{10} \mathrm{Al}_{6} \quad \mathrm{NGMG} 2$ and the $\mathrm{Au}_{61} \mathrm{Ag}_{5} \mathrm{Pd}_{1} \mathrm{Cu}_{19} \mathrm{Si}_{7} \mathrm{Al}_{7}$ NCMA are shown in figures 4(a) and (b). The inset of figure 4(b) presents the images obtained 

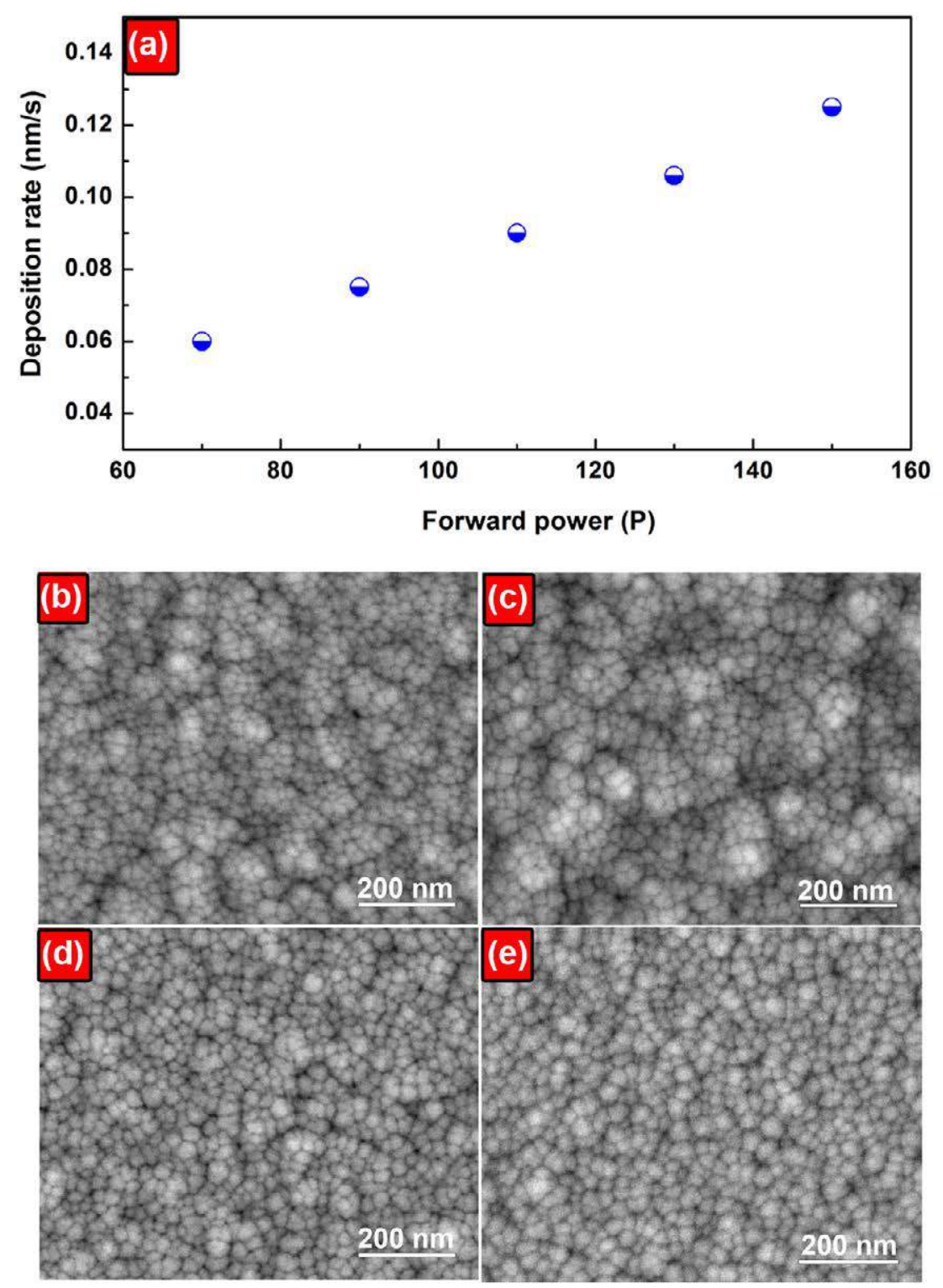

Figure 3. (a) Deposition rate variation with forward power for depositions and SEM images of the thin films deposited at (b) $70 \mathrm{~W}$, (c) $90 \mathrm{~W}$, (d) $130 \mathrm{~W}$ and (e) $150 \mathrm{~W}$.

at high magnifications. The clusters are further composed of nanometer-sized particles of around $30 \mathrm{~nm}$ in diameter. The cluster size distributions of both samples are displayed in figures 4(c) and (d). The crystallized NGMG2 shows a mean cluster size of $143 \mathrm{~nm}$ with a narrower size distribution than NCMA with a mean cluster size of $175 \mathrm{~nm}$ (figures 4(c) and (d)). The shape of the clusters is more spherical-like than those of the NCMA specimen, possibly due to the isotropic growth associated with the glassy structure. One of the typical depth-load curves of the annealed NGMG2 and the NCMA samples is shown in figure 4(e). The corresponding scanning probe microscopy (SPM) images of the indenters are shown in figures $4(\mathrm{~g})$ and $(\mathrm{h})$. Based on five independent measurement points, the average hardness can be derived to be $4.8 \mathrm{GPa}$ and $3.9 \mathrm{GPa}$ for the crystallized NGMG2 and NCMA samples, respectively. The hardness of the as-prepared NGMG2 is around $5.3 \mathrm{GPa}$ [22] while the hardness of the crystallized sample is about $4.8 \mathrm{GPa}$. The lower hardness than the original nanograined glassy structured sample is likely associated with the voids formed during the nanocrystallization process, but the crystallized $\mathrm{Au}_{52} \mathrm{Ag}_{5} \mathrm{Pd}_{2} \mathrm{Cu}_{25} \mathrm{Si}_{10} \mathrm{Al}_{6} \mathrm{NGMG} 2$ sample still exhibited a higher hardness than $\mathrm{Au}_{61} \mathrm{Ag}_{5} \mathrm{Pd}_{1} \mathrm{Cu}_{19} \mathrm{Si}_{7} \mathrm{Al}_{7} \mathrm{NCMA}$, which likely results from their Au concentration difference. It has been reported that higher Au content yields lower hardness of the Au-based metallic glasses [34]. Compared with 3.9 $\mathrm{GPa}$ for the bulk $\mathrm{Au}_{49} \mathrm{Ag}_{5.5} \mathrm{Pd}_{2.3} \mathrm{Cu}_{26.9} \mathrm{Si}_{16.3} \mathrm{BMG}$, the nanocrystallized Au-based NGMG2 shows a higher hardness, of almost three times greater than that of conventional 18-karat crystalline gold alloys [35]. This indicates that the nanometer-sized nanograins having glassy structure indeed hardened the materials, similar to the grain size-strength effect in nanocrystalline materials. In addition, from the depth-load curves, the elastic modulus can be also derived 

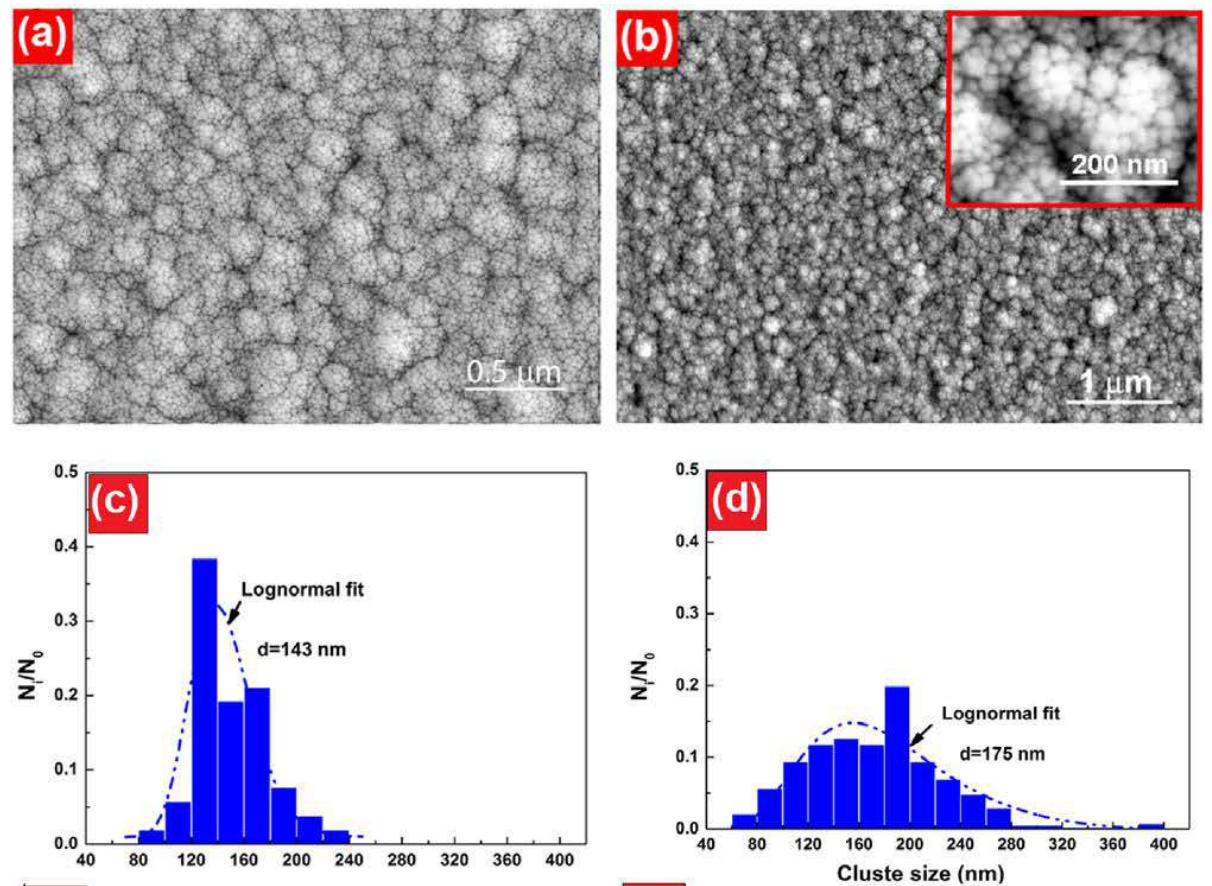

(e)

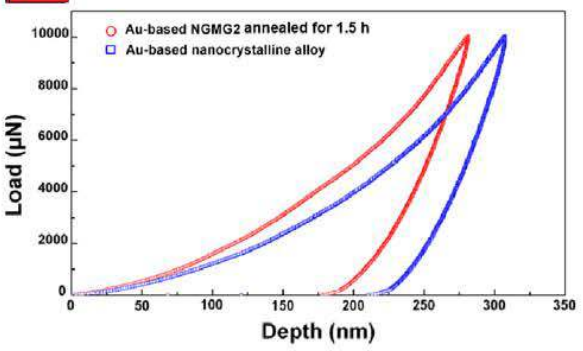

(f)
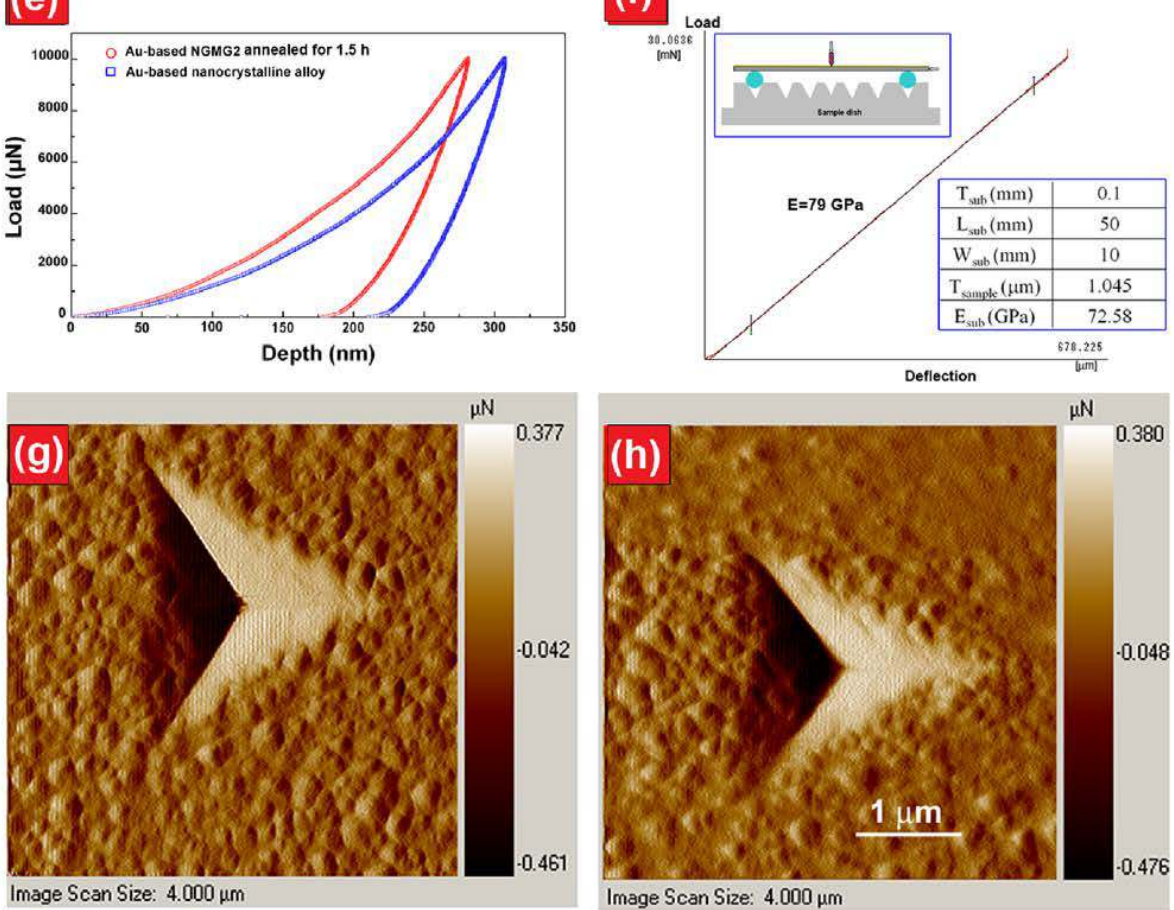

Figure 4. SEM images of (a) the NGMG2 annealed at $463 \mathrm{~K}$ for $1.5 \mathrm{~h}$ and (b) NCMG samples; the inset of (b) is the SEM image at a high magnification. (c), (d) The cluster size distribution analysis of SEM images (a) and (b), respectively. (e), (f) are the corresponding SPM images of the indents for the crystallized NGMG2 and the NCMG samples, respectively. (g) One of the typical depth-load curves derived from nanoindentation tests for both samples. Elastic modulus determination of the NGMG2 based on the principle of a beam-bending test (h) the load-deflection curve of the Au-based NGMG deposited on the standard quartz glass substrate. The left inset is the schematic diagram for elastic modulus measurement and the right insets are the parameters of thickness $(T)$, length $(L)$, width $(W)$ and the elastic modulus $(E)$ of the standard quartz substrate.

to be $108 \mathrm{GPa}$ and $115 \mathrm{GPa}$ for NCMA and the crystallized NGMG2 samples, respectively. Both values are higher than $\sim 70 \mathrm{GPa}$ for the Au-based BMGs $[36,37]$. Indeed there is a tendency to overestimate the Young's modulus of thin films by nanoindentation due to both the substrate and the indentation pile up effects [38]. But the elastic modulus increases with the $\mathrm{Au}$ content increase as the hardness changes, which is also consistent with the results reported in [34].

To obtain a reliable elastic modulus $(E)$ of the as-deposited Au-based NGMG2, we used an alternative 
beam-bending method [39]. The bending deflection for a composite beam is calculated using the following equation:

$$
\frac{\mathrm{d}^{2} Y}{\mathrm{~d} X^{2}}=-M / \sum_{i} E_{i} I_{i}
$$

where $M$ is the bending moment, and $E_{i}$ and $I_{i}$ are the Young's modulus and geometrical moment for the element $i$. The geometrical moments of inertia for a film/substrate composite are given by

$I_{\text {sub }}=b h_{\mathrm{sub}}^{3} / 12$

$I_{\mathrm{tf}}=b h_{\mathrm{sub}}^{2} h_{\mathrm{tf}} E_{\mathrm{sub}}(1+2 \alpha) / 4\left(E_{\mathrm{sub}}+2 \alpha E_{\mathrm{tf}}\right)+b h_{\mathrm{tf}}^{3} / 12$

where the subscripts sub and tf denote the substrate and thin film terms, respectively, $b$ is the substrate width, $h$ is the thickness and $\alpha$ is the thickness ratio $h_{\mathrm{tf}} / h_{\text {sub }}$. The loading point deflection $d_{\mathrm{sub}+\mathrm{tf}}$ at the center of the composite beam can be written as

$$
d_{\mathrm{sub}+\mathrm{tf}}=F l^{3} / 48\left(E_{\mathrm{sub}} I_{\mathrm{sub}}+E_{\mathrm{tf}} I_{\mathrm{tf}}\right)
$$

where $F$ denotes the load. By combining equations (2) and (3), equation (4) can be rewritten as

$$
\begin{aligned}
F= & 4 b h_{\mathrm{sub}}^{3}\left[E_{\mathrm{sub}}+E_{\mathrm{tf}} \alpha^{3}\right. \\
& \left.+3 E_{\mathrm{sub}} E_{\mathrm{tf}} \alpha(1+2 \alpha) /\left(E_{\mathrm{sub}}+2 \alpha E_{\mathrm{tf}}\right)\right] d_{\mathrm{sub}+\mathrm{tf}} .
\end{aligned}
$$

As shown in figure 4(f), by linear fitting the data of 521 experimental points located within the range between the two marks, the $E$ of the sample is derived to be $\sim 79 \mathrm{GPa}$. The combination of the high hardness and low $E$ value indicated that the Au-based NGMG2 maintained the good mechanical properties of the Au-based BMGs [35-37].

Recently the sample size effect on the mechanical response of metallic glasses has been the focus of theoretical and experimental investigations [40-47]. Reducing the sample size is supposed to drive metallic glasses to deform homogeneously. Regarding the deformation mode via homogeneous or inhomogeneous plastic flow, however, a paradoxical debate has been aroused when the sample size is reduced to the nanoscale [43, 44]. The main concern responsible for this controversy is attributed to the size limitation associated with the focused ion beam (FIB) fabrication method, which also imposes an extrinsic effect such as $\mathrm{Ga}^{+}$implantation on the experimental reliability [48, 49]. An alternative way to produce nanometer-sized samples for mechanical testing is thus necessary to avoid the unwanted extrinsic effects. Now, using the deposition approach we have developed, the Au-based NGMGs were synthesized with a particle size of only $\sim 30 \mathrm{~nm}$, which is comparable with the size scale of shear bands, normally of the order of several tens of nanometers [44]. Thus, the nanoglassy particles would be an ideal material to test the size effect on the mechanical response of metallic glasses. We used a spherical indenter tip to intentionally deform the NGMA1 sample. Because the load on the material is asymmetrical due to the surface height fluctuations, a tensile stress is induced at some sites. Along the tensile direction, the nanoglassy particles are stretched and the plasticity mainly originates from the elongation of
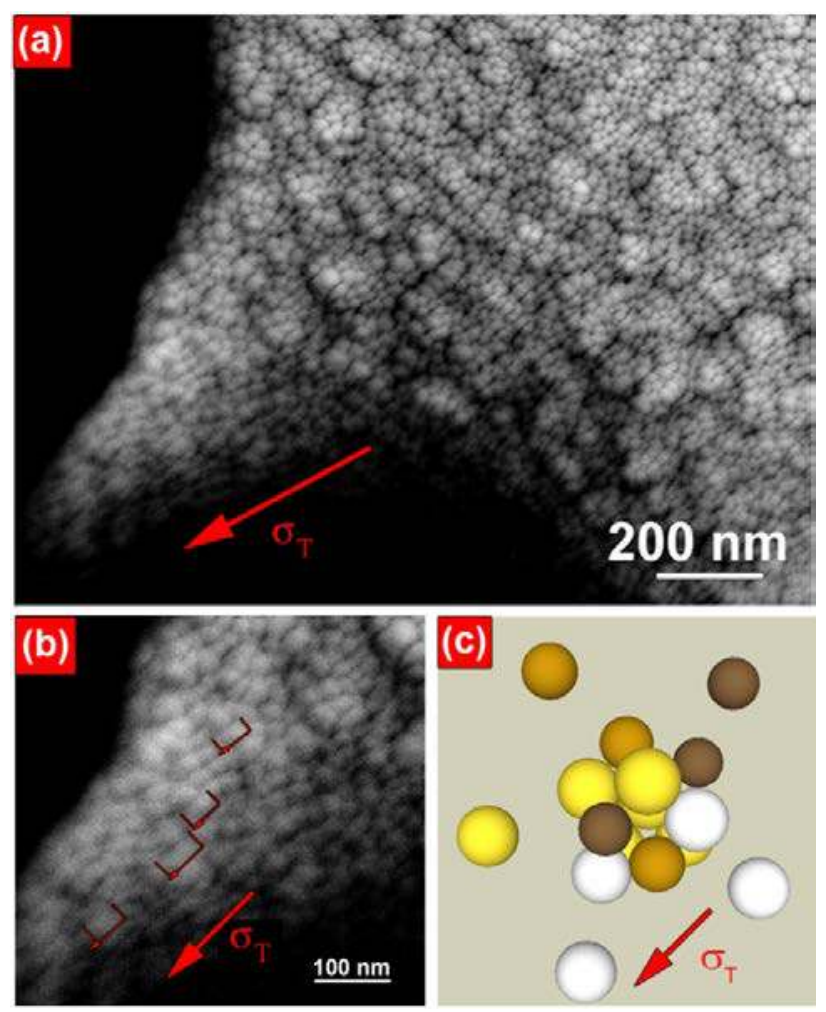

Figure 5. (a) An SEM micrograph demonstrating the elongation of the nanoglassy particles of the NGMG1 sample along the stress direction (arrow). (b) Enlarged view of the elongated nanoglassy particles indicated by brackets. (c) Schematic illustration of the deformation of nanoglassy particles.

the particles (figures 5(a) and (b)). In addition, the particles, particularly those located at the tip of the deformation front, are elongated to almost twice the original length along the deformation orientation (highlighted by the red arrows in figure $5(\mathrm{~b})$ ). It is suggested that nanoglassy particles have denser atomic packing than the interfaces around them (figure 5(c)). When the particles are subjected to the applied tensile stress, the particles would elongate in unison to exhibit high ductility.

\subsection{Nanograin structural morphology}

A closer examination of nanoglass morphology as displayed in images such as that shown in figure 4(a) reveals typical fractal features of self-similarity at different scales. For example, a fractal analysis using a known formula:

$$
D=-\frac{\mathrm{d} \ln N(\varepsilon)}{\mathrm{d} \ln \varepsilon} \approx \frac{\ln (m)}{\ln (r)},
$$

where $N(\varepsilon)$ is the amount of covering of size $\varepsilon, m$ is the number of repetitions of the reduced fractal pattern of size $r$, which gives fractal dimension $D$ of 1.8 for 1 bit black and white images and 2.8 for a grayscale image [50]. Although it is a $2 \mathrm{D}$ representation of a $3 \mathrm{D}$ structure, it represents a fractal (self-similar) nature of the structural morphology. During thin film deposition, island structure genesis can evolve through various mechanisms such as diffusion controlled aggregation 
or by physical contact [51]. With the latter process the island (or grain) size distribution can develop a bimodal character. In the case of the NGMG, the structures in figures 1(a), (f), 4(a) and in prior work [22] reveal a bimodal character composed of nanoglassy grains and nanograin assemblies that are consistent with the observed self-similar behavior.

In conclusion, the unusually stable Au-based NGMG having nanoglassy granular structure shows an elastic modulus of $\sim 79 \mathrm{GPa}$ and a hardness of $\sim 5.3 \mathrm{GPa}$, so that they are stronger and more elastic than the crystalline counterparts and display high ductility. The attributes of an optimum combination of high strength, high hardness and large surface area are attractive for numerous applications in the areas of coatings, catalysis and electronics. When subjected to an annealing treatment, smaller nanocrystals precipitated from the nanometer-sized glassy grains, which provides an alternative way to produce new crystalline materials with tailored length scale.

\section{Acknowledgments}

This work was supported by the World Premier International Research Center Initiative (WPI), MEXT, Japan and partially supported by the Research and Development Project on Advanced Materials Development and Integration of Novel Structured Metallic and Inorganic Materials from the Ministry of Education, Culture, Sports, Science and Technology, Japan. JHP is grateful also for support from ONR (N00014-12-10569) in this area.

\section{References}

[1] Klement W, Willens R H and Duwez P O L 1960 Nature $187869-70$

[2] Chen H S 1980 Rep. Prog. Phys. 43 353-432

[3] Inoue A 1995 Mater. Trans. JIM 36 866-75

[4] Inoue A 2000 Acta Mater. 48 279-306

[5] Greer A L 1995 Science 267 1947-53

[6] Johnson W L 1999 MRS Bull. 24 42-56

[7] Inoue A, Kita K, Zhang T and Masumoto T 1989 Mater. Trans. JIM 30 722-5

[8] Peker A and Johnson W L 1993 Appl. Phys. Lett. 63 2342-4

[9] Wang W H, Dong C and Shek C H 2004 Mater. Sci. Eng. R 44 45-89

[10] Axinte E 2012 Mater. Des. 35 518-56

[11] Axinte E M and Chirileanu M P I 2012 Recent Patents on Mater. Sci. 5 213-21

[12] Kumar G, Tang H X and Schroers J 2009 Nature 457 868-72

[13] Yu H B, Shen X, Wang Z, Gu L, Wang W H and Bai H Y 2012 Phys. Rev. Lett. 108015504

[14] Pauly S, Goranla S, Wang G, Kuhn U and Eckert J 2010 Nature Mater. 9 473-7

[15] Hofmann D C, Suh J Y, Wiest A, Duan G, Lind M L, Demetriou M D and Johnson W L 2008 Nature 451 1085-9
[16] Wang H, Xing D W, Peng H X, Qin F X, Cao F Y, Wang G Q and Sun J F 2012 Scr. Mater. 66 1041-4

[17] Qu R T, Zhao J X, Stoica M, Eckert J and Zhang Z F 2012 Mater. Sci. Eng. A 534 365-73

[18] Hall E O 1950 Proc. Phys. Soc. B $64747-53$

[19] Petch N J 1953 J. Iron Steel Inst. 174 25-8

[20] Jing J, Kramer A, Birringer R, Gleiter H and Gonser U 1989 J. Non-Cryst. Solids 113 167-70

[21] Gleiter H 1989 Prog. Mater. Sci. 33 223-315

[22] Chen N et al 2011 Acta Mater. 59 6433-40

[23] Ruffino F, Torrisi V, Marletta G and Grimaldi M G 2010 Appl. Phys. A $1007-13$

[24] Louzguine-Luzgin D V, Georgarakis K, Zadorozhnyy V, Chen N, Nakayama K, Vaughan G, Yavari A R and Inoue A 2012 Intermetallics 20 135-40

[25] Guo Y, Morozov A, Schneider D, Chuang J W, Zhang C, Waldmann M, Yao N, Fytas G, Arnold B and Priestley R D 2012 Nature Mater. 11 337-43

[26] Ediger M D and Yu L 2012 Nature Mater. 11 267-8

[27] An Q, Luo S N, Goddard W A, Han W Z, Arman B and Johnson W L 2012 Appl. Phys. Lett. 100041909

[28] Swallen S F, Kearns K L, Mapes M K, Kim Y S, Mcmahon R J, Ediger M D, Wu T, Yu L and Satija S 2007 Science 315 353-6

[29] Angell C A 1995 Science 267 1924-35

[30] Stillinger F H 1995 Science 267 1935-9

[31] Debenedetti P G and Stillinger F H 2001 Nature 410 259-67

[32] Chen H S 1978 J. Appl. Phys. 49 3289-91

[33] Glieter H 2008 Acta Mater. 56 5875-93

[34] Guo H, Zhang W, Chen M W, Saotome Y, Fukuhara M and Inoue A 2011 Metall. Mater. Trans. A 42A 1486-90

[35] Shroers J, Lohworgwatana B, Johnson W L and Peker A 2005 Appl. Phys. Lett. 87061912

[36] Johnson W L and Samwer K 2005 Phys. Rev. Lett. 95195501

[37] Yang B and Nieh T G 2007 Acta Mater. 55 295-300

[38] Chu J P et al 2012 Thin Solid Films 520 5097-122

[39] Tsukamoto Y, Yamaguchi H and Yanagawa M 1987 Thin Solid Films 154 171-81

[40] Sond S X, Jang J S C, Huang J C and Nieh T G 2010 Intermetallics 18 702-9

[41] Lee C J, Huang J C and Nieh T G 2007 Appl. Phys. Lett. 91161913

[42] Schuster B E, Wei Q, Ervin M H, Hruszkewycz S O, Miller M K, Hufnagel T C and Ramesh K T 2007 Scr. Mater. 57 517-20

[43] Volkert C A, Donohue A and Spaepen F 2008 J. Appl. Phys. 103083539

[44] Shan Z W, Li J, Cheng Y Q, Minor A M, Syed Asif S A, Warren O L and Ma E 2008 Phys. Rev. B 77155419

[45] Wu X L, Guo Y Z, Wei Q and Wang W H 2009 Acta Mater. $573562-71$

[46] Chen C Q, Pei Y T and De Hosson J T M 2010 Acta Mater. 58 189-200

[47] Luo J H, Wu F F, Huang J Y, Wang J Q and Mao S X 2010 Phys. Rev. Lett. 104215503

[48] Guo H, Yan P F, Wang Y B, Tan J, Zhang Z F, Sui M L and Ma E 2007 Nature Mater. 6 735-9

[49] Jang D C and Greer J R 2010 Nature Mater. $9215-9$

[50] Zmeskal O, Nezadal M and Buchnicek M 2003 Chaos Solitons Fractals 17 113-9

[51] Family F and Meakin P 1988 Phys. Rev. Lett. 61 428-31 